\title{
Internacionalização da educação superior: a dimensão intercultural e o suporte institucional na avaliação da mobilidade acadêmica
}

\author{
Maria Beatriz Luce \\ Caterine Vila Fagundes \\ Olga González Mediel
}

Resumo: Aos países em desenvolvimento, a internacionalização, também educativa, é um processo desafiador para uma soberana inserção no mundo globalizado. Sendo a mobilidade acadêmica um dos meios de internacionalização, torna-se imperativo definir os objetivos nacionais e institucionais que se deseja alcançar com a mobilidade para que se possa definir objetivamente os critérios de qualidade deste processo. Neste artigo, abordamos este processo valorando na mobilidade acadêmica a dimensão intercultural, como um de seus pilares qualitativos. Além de situar em breves traços a mobilidade acadêmica no Brasil e em uma de suas universidades que se destaca em políticas de internacionalização, apresentamos um estudo exploratório realizado através de análise documental e de um questionário que teve como objetivo conhecer o grau de satisfação dos alunos que estão em mobilidade bem como as ações desta universidade para promover a qualidade da formação acadêmica. A conclusão a que chegamos é que são frágeis e incipientes as ações institucionais que promovem a qualidade da mobilidade incoming dos estudantes em sala de aula como nas atividades estudantis e de extensão.

Palavras-chave: Internacionalização. Mobilidade acadêmica. Educação intercultural.

\section{Internationalisation of High Education: the intercultural dimension and the institutional support in the academic mobility evaluation}

Abstract: To the developing countries, the internationalisation, educational as well, is a defying process to the sovereign insertion in a globalised world. Being academic mobility one of the possible ways to internationalisation, it becomes imperative to define the national and institutional objectives of this mobility, so that the criteria for this quality process could be clearly defined. In this paper, we will discuss this process highlighting the intercultural dimension in the academic mobility as one of its qualitative pillars. Beyond briefly commenting the academic mobility in Brazil and also in one of its major universities that is prominent in internationalisation policies, we will present an exploratory study that employed documental analysis and a questionnaire, designed to learn about students' satisfaction with mobility as well as the university's actions to promote academic excellence. Our conclusion is that the institutional actions that promote the quality of student incoming mobility in classroom as well as in other students' activities and academic extension programmes are fragile and incipient.

Key words: Internationalization. Academic mobility. Intercultural education. 


\section{Introdução}

Já adentrando a segunda década do século XXI, a educação superior segue com novos desafios programáticos, isto é, relativos ao conteúdo e ao modo de realizar sua missão de produção intelectual e formação das novas gerações em face, sobretudo, da configuração econômica e política derivada da globalização do capital. Nesse contexto, a mais marcante experiência advém da União Europeia, consolidada em 1991, que revolucionou a economia de mercado e a mobilidade de bens e pessoas, tornando imprescindível a equiparação e, consequentemente, gerando uma elevada homogeneização dos sistemas de formação profissional entre os países signatários dos vários acordos de integração econômica e política. Em 1999, os ministros de educação dos países membros da União Europeia assinaram a Declaração de Bolonha para fazer convergir seus sistemas universitários e atualizar a qualidade e competitividade desses no cenário mundial. Tal acordo desencadeou uma gigantesca e complexa reforma universitária em todos os países signatários no sentido de adotar princípios e critérios comuns nas suas estruturas curriculares como na avaliação e acreditação institucional, tendo a mobilidade docente e estudantil como uma estratégia vital de motivação para o desenvolvimento da educação superior no Velho Continente.

Com efeito, o processo de Bologna - como vimos a denominar o conjunto das políticas firmadas em sucessivos anos e distintas localidades por um grupo cada vez mais alargado de universidades europeias - entre outros objetivos construiu efetivamente condições de ampliação e intensificação da mobilidade acadêmica contribuindo para as novas e diversificadas realidades do mercado de trabalho na Europa e colaborando para a atratividade dos cursos europeus, tanto para seus nativos quanto para os jovens de outras regiões. Assim observava, já em 2005, Dias Sobrinho ao problematizar o seu sentido político e educativo: sociedade do conhecimento ou economia do conhecimento?

A criação do Espaço Europeu de Educação Superior, além de construir condições para ampliar e intensificar a mobilidade acadêmica naquele continente, impulsionou a dimensão internacional da Educação Superior e, de modo axiomático, na América Latina - em especial, no Brasil (DIAS SOBRINHO, 2009; VEGA, 2009; CATANI, 2010). Nesta direção, a par de iniciativas institucionais, tem sido crescentes as ações governamentais nas atuais políticas de internacionalização da educação superior, sendo a mobilidade acadêmica considerada uma estratégia importante para a formação educativa, por proporcionar a aquisição de conhecimentos e habilidades essenciais para que 
Internacionalização da educação superior: a dimensão intercultural e o suporte institucional na avaliação da mobilidade acadêmica

os sujeitos possam experimentar, na condição de estudantes e professores, o mundo globalizado, interagir no mercado multicultural e contribuir para o desenvolvimento social. Porém, é preciso ter presente que a qualidade da mobilidade depende dos objetivos nacionais que com ela se deseja alcançar, para que se possa então definir, inclusive a nível institucional, seus critérios de qualidade. Por conseguinte, é de fundamental relevância avaliar as políticas e as ações institucionais no que tange à mobilidade acadêmica, com o intuito de qualificar a oferta e assim instigar estudantes do exterior a vir em mobilidade para as universidades brasileiras.

Com tal perspectiva, que é adiante fundamentada, realizamos um estudo para conhecer a satisfação dos alunos que estão em mobilidade na Universidade Federal do Rio Grande do Sul (UFRGS), bem como as ações desenvolvidas por essa universidade para promover a qualidade da mobilidade incoming e de sua dimensão intercultural. Em termos metodológicos, este estudo, de caráter exploratório, foi realizado em diferentes fases.

Primeiramente, procedemos à revisão da literatura existente sobre o assunto para compreender as distintas conceitualizações sobre a internacionalização da educação superior e a mobilidade acadêmica, com o propósito de destacar a dimensão intercultural do processo. Posteriormente, realizamos a tradução, a adaptação e a validação para uso no Brasil de um questionário online para verificar a satisfação dos alunos de programas de mobilidade, oriundo da Universidade de Santiago de Compostela. Finalmente, aplicamos o instrumento aos 137 alunos em mobilidade incoming, no âmbito do ensino de graduação, no período de março a julho de 2014. Destes, obtivemos um total de 56\% de respostas que proporcionaram conhecer a qualidade das políticas e práticas institucionais no que se refere à mobilidade incoming que, por sua vez, traduz a perspectiva de internacionalização do país de destino dos estudantes.

\section{A internacionalização da Educação Superior}

Ao abordar a internacionalização da educação superior torna-se substancial precisar o conceito, uma vez que Altbach (2004) manifesta que muitas vezes se confunde internacionalização com globalização. Por esta razão, as distinções e definições a respeito de ambos conceitos são objeto de análise de diversos autores (DALE, 2004; ENDERS, 2004; ALTBACH; KNIGHT, 2007; LIMA; MARANHÃO, 2009; ROBERTSON, 2009; DE WIT, 2011). Sendo assim, estamos de acordo com Altbach e Knight (2007), quando assinalam que a globalização se relaciona com o contexto de tendências econômicas e 
acadêmicas do século XXI e que, no campo da educação superior, a internacionalização é o conjunto de políticas e práticas desenvolvidas pelos sistemas acadêmicos, pelas instituições e pelos indivíduos para fazer frente ao ambiente acadêmico global.

Compreendemos que a criação do Espaço Europeu de Educação Superior pôs em marcha novos desafios e propósitos para a universidade, não somente na Europa, mas também em outras partes do mundo. Após o processo de Bolonha, busca-se consolidar ações que atendam às demandas educativas do mundo globalizado. Centrando-se na América Latina e seguindo esta linha de atuação, tem-se a afirmação de Gacel-Ávila (2005) de que a internacionalização é uma das estratégias educativas e políticas mais inovadoras e complexas na qual se empenham as instituições de educação superior de países que enfrentam o desafio de atualizar seus sistemas educativos. Sobre o estado da internacionalização na América do Sul, Botto (2015), em recente pesquisa, conclui que os países estão promovendo seus processos de reforma e consolidando suas capacidades nacionais, mas que ainda não conseguiram estabelecer um espaço regional de educação superior.

Sendo a internacionalização um recurso que impulsiona os sistemas e instituições de educação superior a responder às necessidades educativas do mundo globalizado, para os países em desenvolvimento, como o Brasil, investir na internacionalização da educação superior é, sem lugar a dúvidas, um processo fundamental para a sua inserção no mundo globalizado, em condições de soberania.

Entretanto, é mister assinalar que a internacionalização não ocorre do mesmo modo em todos os contextos, pois é um processo que tem diferentes significados conforme a situação. Segundo Lima e Maranhão (2009), o processo de internacionalização ocorre: pela internacionalização ativa, quando as políticas dos países se voltam para receber os alunos em mobilidade e oferecer serviços educacionais no exterior, exportar e instalar campus em outros países; e por meio da internacionalização passiva, que se caracteriza pela inexistência de uma política clara para o envio de alunos para outros países, os quais não possuem recursos materiais e humanos para receber e oferecer este tipo de serviços educativos. De acordo com Knight (2010, p. 1) e Castro e Cabral Neto (2012), o modo como os países e regiões se inserem no cenário mundial, segundo sua importância política, desenvolvimento econômico, científico e tecnológico, influi no processo de receber os alunos em mobilidade.

A propósito, Knight (2010, p. 1) apresenta um resumo das diferentes interpretações sobre a internacionalização: 
[...] para alguns, significa uma serie de atividades, tais como: a mobilidade acadêmica de estudantes e de professores, redes internacionais, associações e projetos, novos programas acadêmicos e iniciativas de investigação. Para outros, significa a transmissão da educação a outros países através das novas disposições, como sucursais ou franquias de universidades, usando uma variedade de técnicas presenciais e à distância. Para muitos, significa a inclusão de uma dimensão internacional, intercultural e/ou global dentro do currículo e o processo de ensino-aprendizagem. E, outros, concebem a internacionalização como centros regionais de educação, hot spots, redes de conhecimento. Os projetos de desenvolvimento internacionais são percebidos tradicionalmente como parte da internacionalização e, mais recentemente, o aumento na ênfase no comércio da educação superior também está sendo visto como internacionalização. ${ }^{1}$

Conforme afirma Veiga (2012, p. 8) "a internacionalização se interpreta e é utilizada de forma diferente em distintos países". Entendemos nós que, no Brasil, a principal (se não exclusiva) perspectiva sobre a internacionalização é a mobilidade de estudantes, professores e pesquisadores. Em menor medida, a promoção de equipes de cooperação.

\section{A mobilidade acadêmica como estratégia de internacionalização da educação superior}

Na Declaração Mundial de Educação Superior, aprovada no transcurso da conferência da UNESCO (1998), se afirma ao artigo 11, parágrafo D, que:

A qualidade requer também que o ensino superior esteja caracterizado por sua dimensão internacional: o intercâmbio de conhecimentos, a criação de sistemas interativos, a mobilidade de professores e estudantes e os projetos de investigação internacionais, ainda quando se tenha devidamente em conta os valores culturais e as situações nacionais.

Quanto à dimensão internacional da educação superior, com Teichler (2004) podemos asseverar que a mobilidade é uma das principais formas de internacionalização. Mas, ainda que a mobilidade acadêmica seja o elemento mais visível e amplamente analisado da internacionalização, conforme avalia Van Damme (2001), é necessário ter presente que a internacionalização não se limita à mobilidade. A mobilidade ajuda no processo, mas a longo prazo e, por esta razão, é importante ter claro os objetivos nacionais que se deseja alcançar

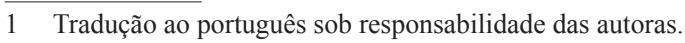


com a mobilidade para que se possa definir, inclusive a nível institucional, seus critérios de qualidade. Nesta direção reflete Dias Sobrinho:

a qualidade da educação superior não pode ser pensada fora das ações e dos compromissos que cada instituição instaura em seu âmbito interno e nas suas vinculações com o entorno mais próximo, com a sociedade nacional, com os contextos internacionais do conhecimento e com o Estado Nacional (2010, p. 1228).

Desta maneira, para assegurar a qualidade é preciso estabelecer prioridades, é necessário definir os critérios e/ou objetivos que se pretende lograr com a mobilidade, respeitando as características de cada sistema.

Nesta perspectiva, faz-se relevante tipificar a mobilidade acadêmica e assim precisar o âmbito deste estudo. Conforme elucidado no Relatório de Implementação do Processo de Bolonha, no item que se refere à mobilidade internacional de estudantes e metas de mobilidade (2015), há dois tipos de mobilidade: a mobilidade de grau, quando os alunos que vão cursar seus estudos integralmente em outro país, fazendo jus a um título condizente coma formação do país de destino; e a mobilidade de crédito, através da qual os alunos regularmente matriculados em uma instituição de educação superior, no país de residência, vão cursar uma parte do seu programa acadêmico em outra instituição no exterior e, posteriormente, os créditos lá obtidos são reconhecidos pela instituição de origem. Existem diversos programas que viabilizam a mobilidade de créditos, sendo o Programa Erasmus o mais conhecido na Europa e o Ciência sem Fronteiras, no Brasil (2011). Ademais, no relatório em tela está caracterizada a direção dos fluxos de mobilidade. A mobilidade externa (outward mobility) assume a perspectiva do país de origem do estudante, sendo uma alta taxa de fluxo considerada como um indicador de uma política proativa para que os alunos adquiram experiência internacional (particularmente para a mobilidade de crédito). No entanto, também pode ser um indicador de possíveis insuficiências no sistema de ensino do país de origem (particularmente para a mobilidade grau). Em outra direção está a mobilidade interna (incoming mobility), que assume a perspectiva do país de destino, para onde o aluno se desloca para estudar. A alta taxa de mobilidade incoming pode ser considerada um indicador da atratividade do país e/ou da instituição, analisada proporcionalmente ao tamanho do sistema de ensino superior.

O escopo do presente estudo é avaliar a qualidade da mobilidade incoming que, por sua vez, traduz a perspectiva de internacionalização do país de destino dos estudantes tendo presente que a qualidade da mobilidade depende 
dos objetivos nacionais que se deseja alcançar com a mobilidade para que se possa definir, inclusive a nível institucional, seus critérios de qualidade. Por conseguinte, é de fundamental relevância qualificar a oferta para fomentar o interesse de estudantes estrangeiros em vir em mobilidade para as instituições de educação superior brasileiras.

Sobre os números da mobilidade acadêmica na América Latina e no Brasil, de acordo aos dados da Unesco (2015), o Brasil tem atualmente 32,051 mil estudantes em mobilidade no exterior, o que representa $0,4 \%$ da taxa global dentre os países que enviam alunos ao exterior; e recebe, neste momento, 15,221 mil estudantes, o que representa $0,2 \%$ da taxa global no que se refere a recepção de alunos do exterior, conforme podemos observar no Quadro 1.

\section{Quadro 1 - Países da América Latina mais representativos no envio e recepção de estudantes $(\mathbf{2 0 1 5})^{2}$}

\begin{tabular}{|c|c|c|c|c|}
\hline PAÍS & $\begin{array}{c}\text { TOTAL DE ALUNOS QUE } \\
\text { VÃO EM MOBILIDADE } \\
(\% \text { MOB. GLOBAL })\end{array}$ & $\begin{array}{c}\text { DESTINO } \\
\text { (principais } \\
\text { destinos) }\end{array}$ & $\begin{array}{c}\text { TOTAL ALUNOS } \\
\text { QUE ESTÃO EM } \\
\text { MOBILIDADE NO PAÍS } \\
(\% \text { MOB. GLOBAL) }\end{array}$ & $\begin{array}{c}\text { ORIGEM } \\
\text { (principais } \\
\text { origens) }\end{array}$ \\
\hline BRASIL & $32.051(0.4 \% \text { M.G. })^{3}$ & USA & $15,221(0.2 \%$ M.G. $)$ & ANGOLA \\
\hline MÉXICO & $26.866(0.8 \%$ M.G. $)$ & USA & - & - \\
\hline COLOMBIA & $23.602(0.7 \%$ M.G. $)$ & USA & - & - \\
\hline PERÚ & $14.844(0.4 \%$ M.G. $)$ & ESPANHA & - & - \\
\hline VENEZUELA & $11.720(0.3 \%$ M.G. $)$ & USA & - & - \\
\hline ARGENTINA & $8.084(0.2 \%$ M.G. $)$ & ESPANHA & - & - \\
\hline
\end{tabular}

Fonte: UNESCO. Global Flow of Tertiary-Level Students. 2015. Disponível em: $<$ http://www.uis.unesco. org/EDUCATION/Pages/international-student-flow-viz.aspx>. Acesso em: 5 ago. 2015.

Cabe destacar que esses números se referem aos alunos que estão em mobilidade de grau, excluindo os alunos que estão em mobilidade de créditos pois ainda não existem dados precisos sobre este tipo de mo-

2 Estão excluídos os alunos que vão em mobilidade pelo programa Ciência sem Fronteiras.

3 Porcentagem da mobilidade referente aos números da porcentagem da mobilidade global. Segundo a UNESCO: "These data cover only students who pursue a higher education degree outside their country of residence (so-called "degree mobility") and exclude students who are under short-term, for-credit study and exchange programmes that last less than a full school year (so-called "credit mobility")"(UNESCO, 2015). 
bilidade. Evidencia-se que a taxa de estudantes estrangeiros no Brasil é baixa nos cursos de graduação $(0,2 \%)$, em comparação aos países com mais tradição em mobilidade, porém bastante expressiva em nível de pós-graduação, uma vez que recebe $2 \%$ dos estudantes de outros países (UNESCO, 2015) ${ }^{4}$. Recentemente, o Brasil começou a destacar-se no cenário da internacionalização da educação superior devido ao grande investimento em mobilidade acadêmica externa, impulsionado pelo programa Ciência sem Fronteiras ${ }^{5}$. Entretanto, o desafio está posto também no que concerne à mobilidade incoming posto que o afluxo de estudantes é imprescindível para a efetiva internacionalização da educação superior. Neste sentido, para conhecer a eficácia dos esforços investidos em mobilidade, é oportuna uma avaliação que considere as diversas dimensões relacionadas com a mobilidade dos estudantes. Atualmente e, em geral, quando se analisa a qualidade da educação superior com relação à mobilidade, não se avalia a mobilidade, mas a qualidade dos programas. Todavia, na América Latina e, no caso do Brasil, não existe uma cultura da avaliação da qualidade relacionada com a internacionalização da aprendizagem. Sendo assim estamos em tempo de incorporar critérios qualitativos no processo. É a partir desta ótica que se pretende que as instituições contribuam a desenvolver a dimensão intercultural presente na mobilidade acadêmica.

\section{A Interculturalidade como Característica de Qualidade na Mobilidade Acadêmica}

A dimensão intercultural é uma característica de qualidade intrínseca à mobilidade acadêmica que, por sua vez, é um dos meios do processo de internacionalização da educação superior, a mobilizar um grande fluxo estudantil nos cinco continentes. Tendo em vista tamanha diversidade e, nesta perspectiva, atender as demandas do mundo globalizado, as instituições de educação superior estão empenhadas em qualificar tanto as políticas institucionais como uma série de questões práticas para receber estudantes internacionais capacitados, que buscam excelência em diferentes espaços

4 Os Estados Unidos recebem 18\% dos estudantes em mobilidade, o Reino Unido 11\%, França 7\%, Austrália $6 \%$ e Alemanha 5\%. (UNESCO, 2015).

5 Iniciado em julho de 2011, o programa Ciência sem Fronteiras "busca promover a consolidação, a expansão e a internacionalização da ciência e da tecnologia, a inovação e a competitividade brasileira através do intercâmbio e da mobilidade internacional". No marco das políticas públicas para a qualidade da educação, o CsF é, na atualidade, o principal programa de intercâmbio e mobilidade acadêmica no Brasil (BRASIL, 2015). 
Internacionalização da educação superior: a dimensão intercultural e o suporte institucional na avaliação da mobilidade acadêmica

de aprendizagem. Neste processo, torna-se importante valorar a dimensão intercultural da mobilidade acadêmica, com o convencimento de que este é elementar na qualidade da mobilidade.

A UNESCO (2005) reconheceu, através da Convenção para a Proteção e Promoção da Diversidade das Expressões Culturais (2005), que a diversidade cultural é uma característica inerente à humanidade, que promove um mundo rico e variado, o qual proporciona o desenvolvimento sustentável das comunidades, dos povos e das nações. Salienta que a diversidade cultural se fortalece através dos intercâmbios, lembrando da diversidade linguística como elemento fundamental da diversidade cultural. Especificamente, no artigo 2 da convenção (2005, p. 6) é apontado que: “Tendo em conta que a cultura é um dos principais motores do desenvolvimento, os aspectos culturais deste, são tão importantes como seus aspectos econômicos, sobre os quais os indivíduos e povos tem o direito fundamental de participação e desfrute".

Em consonância com este entendimento os sistemas educacionais-buscam revisar suas estratégias para proporcionar resultados construtivos de diversidade. Após várias tentativas de gerir a educação em contextos multiculturais (pluriculturalidade, educação compensatória, educação não racista), o modelo educativo intercultural tem se destacado como um dos mais efetivos nas aulas da escolaridade obrigatória, sendo assim aceito e implementado, mais amplamente, em diversos países europeus. $\mathrm{O}$ enfoque educativo intercultural potencializa a cultura do diálogo e da convivência, e ajuda a desenvolver o sentimento de equidade como condição prévia para o conhecimento e o respeito das diferenças culturais no marco da realidade social. Desde este ponto de vista, o sistema educativo tem como objetivo fundamental que todos os alunos alcancem uma sólida competência cultural, ou seja, que desenvolvam atitudes e aptidões para viver em uma sociedade multicultural, destacando o estabelecimento do diálogo como eixo do trabalho intercultural (GONZÁLEZ MEDIEL, 2009).

A internacionalização da educação superior, no que se refere à mobilidade acadêmica, constitui-se sob diversas dimensões sendo o currículo, a habilidade dos professores e o modo como utilizam suas competências para a aprendizagem do estudante e o conhecimento proporcionado alguns pontos importantes deste processo. Lima e Maranhão (2009), em interessante estudo, afirmam que um dos pressupostos básicos dos discursos de apoio à internacionalização da educação superior é a sua capacidade para promover a competência intercultural em múltiplas culturas, e que este pressuposto teve sua incidência na construção de planos de estudos mais críticos e reflexivos, com a sã intenção 
de transformar as escolas no epicentro das transformações sociais, na busca por condições de vida mais justas para todos. Entretanto, as autoras assinalam que, em lugar de promover a diversidade cultural, a internacionalização tem sido a defesa de uma forma particular de cultura, que busca sua legitimação através da padronização dos planos de estudo, dos currículos, dos programas de viagens, dos idiomas e das experiências culturais, uma espécie de colonialismo cultural, onde países com menos tradição em programas de mobilidade, como o Brasil, deveriam estar cientes, já que, por um lado, se valoriza a interculturalidade como valor aditado, mas, em realidade, o discurso é bastante hegemônico. Nesta linha, muito se discorre sobre a necessidade de "unificação" dos planos de estudo dos cursos universitários para facilitar a mobilidade acadêmica, mas também podemos considerar a diversidade dos planos de estudo como um fator enriquecedor da mobilidade acadêmica, ainda que constatemos uma certa reticência em não se alcançar os conteúdos normativos curriculares, no aproveitamento dos créditos e um certo temor em perder a própria identidade cultural ao abrir o currículo a outras formas de fazer e ser. Sobre as competências dos professores neste processo, tomamos como referência o estudo de Leask (2005), centrado nos professores internacionais e nas características que estes devem ter para promover a aprendizagem em contexto internacional e intercultural. A partir de uma pesquisa qualitativa, a autora analisa a percepção dos professores sobre suas destrezas e as expectativas que os alunos tem com relação aos seus professores internacionais. Conclui, entre outras, que a interação entre os estudantes e entre estudantes e professores nestes cenários é a chave da internacionalização. Ainda, acrescenta que "nesses ambientes, os professores devem ser tanto aprendizes interculturais efetivos como gestores eficazes de um entorno de aprendizagem intercultural" (LEASK, 2005, p. 92). Sendo assim, a autora sugere que os professores internacionais devem ser capazes de trabalhar conteúdos e perspectivas internacionais a partir de exemplos e estudos de caso pertinentes; precisam buscar, avaliar e responder aos diversos feedback (escrita, verbal e não verbal) dos estudantes acerca da eficácia do seu exercício docente; necessitam adaptar os enfoques/conteúdos às necessidades dos alunos para atingir aos objetivos da disciplina; devem refletir sobre as experiências de ensino e aprender com elas. Coloca, também, que os professores necessitam entender que a sua cultura afeta a interação com os alunos; o background (social, cultural e educativos) dos estudantes; o marco cultural da disciplina e a influência dos contextos culturais e nacionais na prática profissional da disciplina. Com relação às tarefas dos professores como gestores de um entorno intercultural, a autora expõe que devem ser ca- 
Internacionalização da educação superior: a dimensão intercultural e o suporte institucional na avaliação da mobilidade acadêmica

pazes de se comunicar eficazmente com estudantes de procedências culturais e linguísticas diversas; adaptar as atividades aos estudantes que aprendem de forma diferente; elaborar atividades de avaliação dos estudantes estrangeiros adequadas às suas possibilidades de manifestação da aprendizagem; proporcionar um feedback aos estudantes sobre como proceder para melhorar a aprendizagem; diversificar as estratégias e ferramentas que contribuam à aprendizagem dos estudantes e integrar os estudantes estrangeiros aos debates e trabalhos em grupo. Em definitivo, a formação dos professores universitários deve contemplar a perspectiva internacional da educação superior para a promoção da qualidade da mobilidade acadêmica.

Díaz García et al. (2010) expõe a necessidade de considerar a competência intercultural no âmbito universitário que pretende, em último termo, que os alunos se beneficiem das experiências de aprendizagem e convivência em outros países. Para tal, as universidades colocam à disposição dos estudantes incluídos nos programas de mobilidade uma série de serviços - alguns comuns a toda a comunidade universitária e outros específicos para eles -, assim como espaços que se constituem em lugares de aprendizagem e de convivência por excelência. Não menos importantes são os espaços onde vivem e se divertem. Os professores, com seus estilos de ensino; os orientadores, com sua assistência; o pessoal administrativo, com a gestão dos acordos acadêmicos; os companheiros e amigos, são todos os recursos humanos de que usufruirão os alunos estrangeiros e com os quais terão que se relacionar durante sua permanência no país de destino. Vemos, pois, que há muitos e variados fatores que interagem e coadjuvam na consecução dos objetivos dos programas de mobilidade. Resulta óbvio que todos os objetivos e fins ora mencionados seriam difíceis de atingir se não se respeita a diversidade linguístico-cultural e os cidadãos não aprendem e conhecem outras línguas e culturas. Isso nos leva ao conceito de competência intercultural aplicada ao campo universitário. Finalmente, importa que a mobilidade não constitui um fim em si mesma, mas é um dos meios que os programas de formação acadêmica elegem para a consecução de seus objetivos. Desde nosso ponto de vista, uma das consequências que contribuem para o êxito dos programas de mobilidade é a integração cultural dos estudantes estrangeiros.

\section{Objetivos e Procedimentos Metodológicos}

Em 2014, a Universidade Federal do Rio Grande do Sul - UFRGS, universidade brasileira de grande porte, teve um total de 30.785 alunos matriculados no ensino presencial de graduação, dos quais 1.006 foram estudantes de mo- 
bilidade incoming, procedentes do exterior e de outros Estados brasileiros ${ }^{6}$. A universidade contava com 900 grupos de pesquisa, 5.419 pesquisadores, 5.036 projetos de pesquisa em andamento, com 37.506 participantes nos 91 projetos culturais (UFRGS em números, 2014), tendo 261 acordos de cooperação (sendo 182 protocolos e 79 convênios). Considerando que esta universidade é umas das mais internacionalizadas do Brasil, porém pouco internacionalizada para os padrões europeus, e partindo do pressuposto de que a perspectiva intercultural é um elemento importante da qualidade da mobilidade, o objetivo central deste estudo foi conhecer a satisfação dos alunos que estão em mobilidade incoming, bem como as ações desta universidade que promovem a qualidade desta mobilidade. Este objetivo parte do questionamento sobre como avaliar a qualidade da mobilidade incoming nas instituições.

Com relação aos procedimentos metodológicos, este estudo, de caráter exploratório, foi realizado em diferentes fases. Em um primeiro momento realizou-se a revisão da literatura existente sobre o tema do estudo para compreender as distintas conceitualizações sobre a internacionalização da educação superior e da mobilidade acadêmica e, em seguida, destacar a dimensão intercultural do processo. Posteriormente efetuou-se a tradução e adaptação de um questionário especificamente elaborado para medir o grau de satisfação dos alunos em mobilidade, com especial atenção à dimensão intercultural, concebida como elemento de qualidade no processo de internacionalização dos estudos. Posteriormente, procedemos à aplicação do questionário a 135 alunos em mobilidade incoming procedentes do exterior7, no âmbito do ensino de graduação, no período de março a julho de 2014. Obtivemos um total de 56\% de respostas.

O título do questionário é "A Motivação e o Grau de Satisfação dos Alunos em Mobilidade na Universidade Federal do Rio Grande do Sul (UFRGS)". O questionário aplicado tratou de coletar os dados referentes ao grau de satisfação dos alunos em mobilidade na UFRGS e estabelece dimensões em relação às características sociodemográficas, socioculturais e econômicas, a qualidade na escolha do curso e a experiência educativa prévia ao acesso à Universidade. Hernández, Fernández e Baptista (1991, p. 13) definem o questionário como "um conjunto de perguntas sobre uma ou mais variáveis a serem medidas (categorias

6 Número total de alunos internacionais, considerando todas as matrículas de estudantes estrangeiros que incluem, além da mobilidade na graduação, matrículas em Português para Estrangeiros (PPE), PEC-G (gerenciado pela PROGRAD), Alunos de Pós-Graduação (incluindo estudantes regulares, sanduíche, PEC-PG, OEA, etc - Todos gerenciados pela PROPG). Considerando todas as matrículas de estudantes estrangeiros na UFRGS (um mesmo aluno pode estar matriculado em modalidades diferentes como mobilidade na graduação e PPE ao mesmo tempo), há 500 a 600 matrículas por semestre, ou seja, de 1000 a 1200 ao ano.

7 Total de alunos em mobilidade incoming procedentes do exterior, no primeiro semestre de 2014. Estes alunos representam $0,44 \%$ do total de alunos matriculados na universidade. 
a descrever)". É um instrumento que tem capacidade de coletar informações variadas em uma única aplicação. Desta forma, o questionário é um recurso útil por sua aceitação conjunta de seções estruturadas, semiestruturadas e abertas (CABRERA; ESPIN, 1986).

\section{Adaptação e Validação do Questionário para a Versão Brasileira}

Foi realizada a tradução (e a retrotradução), a adaptação e a validação do instrumento. O questionário foi traduzido do idioma original - espanhol - para o português, por dois sujeitos bilíngues. Esta tradução foi novamente elaborada segundo o idioma original, neste caso o espanhol, para avaliar os possíveis erros de compatibilidade e de sentido na tradução de termos específicos, a partir da comparação da versão original com a tradução final em português. Após este procedimento, a escala já traduzida para a língua portuguesa foi avaliada por um comitê de professores doutores em Métodos de Pesquisa e Diagnóstico em Educação que relacionaram os itens e os termos que haviam mantido o significado original e, por fim, efetuaram as devidas correções. As principais alterações consistiram na adequação das atividades oferecidas pela UFRGS aos alunos em mobilidade. A versão traduzida e retrotraduzida do questionário foi avaliada quanto ao seu entendimento por professores experts em metodologia de pesquisa, por uma pesquisadora de estudos interculturais, e pelo coordenador de relações internacionais da UFRGS. Foram avaliadas as traduções, assim como a validação de conteúdo das perguntas. $\mathrm{O}$ questionário contém um total de 23 perguntas organizadas em cinco blocos.

\section{Aplicação do instrumento e resultados do estudo}

As ações de internacionalização da UFRGS, no âmbito do ensino de graduação, no que respeita à mobilidade dos alunos que estão presentes no período de março de 2014 a julho de 2014, foram o objeto de estudo privilegiado.

\section{Os sujeitos}

Os sujeitos convidados a responder ao questionário foram o total dos 135 alunos que estavam em mobilidade incoming, no âmbito do ensino de graduação, no período de março de 2014 até julho de 2014 na UFRGS. Desse total de alunos estrangeiros 76 preencheram o instrumento enviado por e-mail pela Secretaria de Relações Internacionais da UFRGS (RELINTER), pelo que obtivemos um total de $56 \%$ de respostas. O perfil dos respondentes foi assim caracterizado: 
a) Idade: A idade dos alunos que estavam em mobilidade na UFRGS e que responderam ao questionário aplicado varia entre 20 e 31 anos, sendo que 64 alunos (84\%) tem entre 20 e 24 anos.

b) Tipo de acordo de cooperação/ programa de mobilidade: Dos 76 alunos que responderam ao questionário, 45 responderam a pergunta referente ao programa de mobilidade ao qual estavam participando. Dentre estes, 38 alunos vieram em mobilidade por acordo bilateral, 15 vieram de modo independente, 6 alunos estavam em mobilidade pelo programa Escala-AUGM, 2 alunos por dupla-diplomação e os demais responderam não saber ou não lembrar ${ }^{8}$.

c) Nacionalidade: Dos 76 alunos que estavam em mobilidade incoming na UFRGS, no período de março de 2014 até julho do mesmo ano, e que responderam ao questionário, 32 provém de países da América do Sul, 29 da Europa, 11 da América Central, 3 da América do Norte e 1 da Ásia, conforme detalhado no gráfico 1 .

\section{Gráfico 1 - Número de alunos por região de procedência na UFRGS no primeiro semestre de 2014.}

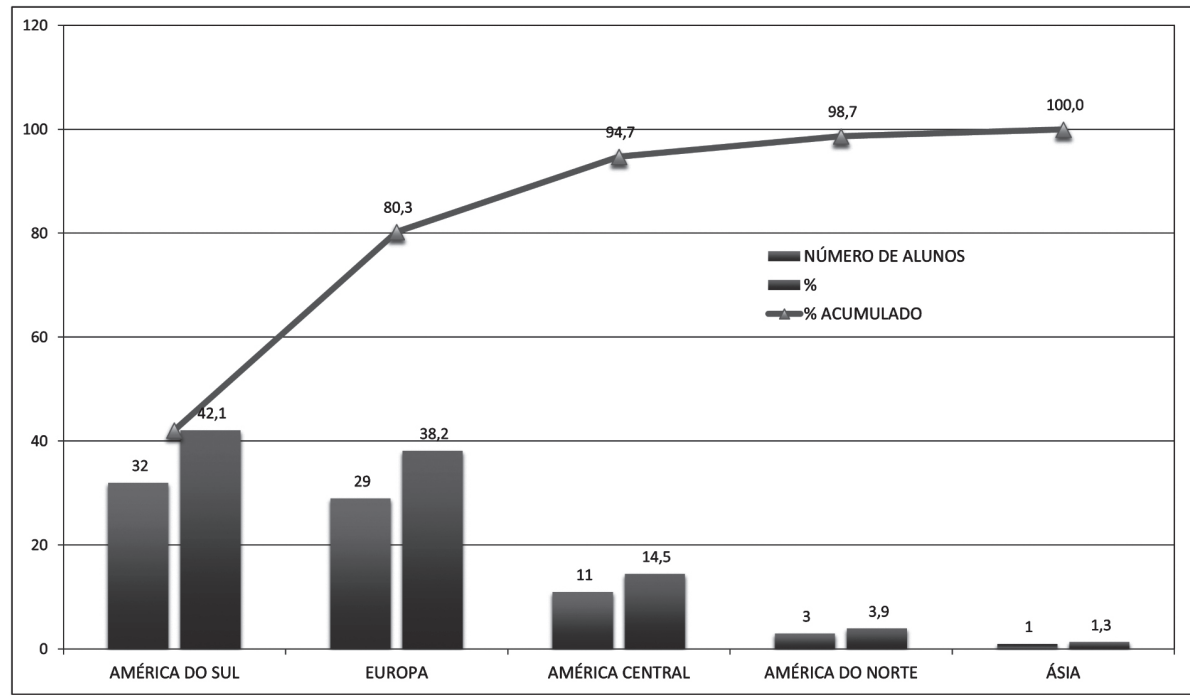

Fonte: elaboração própria.

8 Cabe acrescentar que, de acordo aos dados fornecidos pela RELINTER, do total dos 135 alunos que estavam em mobilidade no período analisado, 72 vieram por acordo bilateral, 33 de modo independente, 15 através do programa Escala-AUGM, 3 por acordo Luso, 5 por acordo Ibérico e 7 por dupla diplomação. 
d) Curso Matriculado: Os cursos mais procurados pelos alunos que vem em mobilidade para a UFRGS são Administração, Arquitetura e Agronomia, conforme podemos observar no gráfico 2 .

\section{Gráfico 2 - Número de alunos matriculados por curso, no primeiro semestre} de 2014.

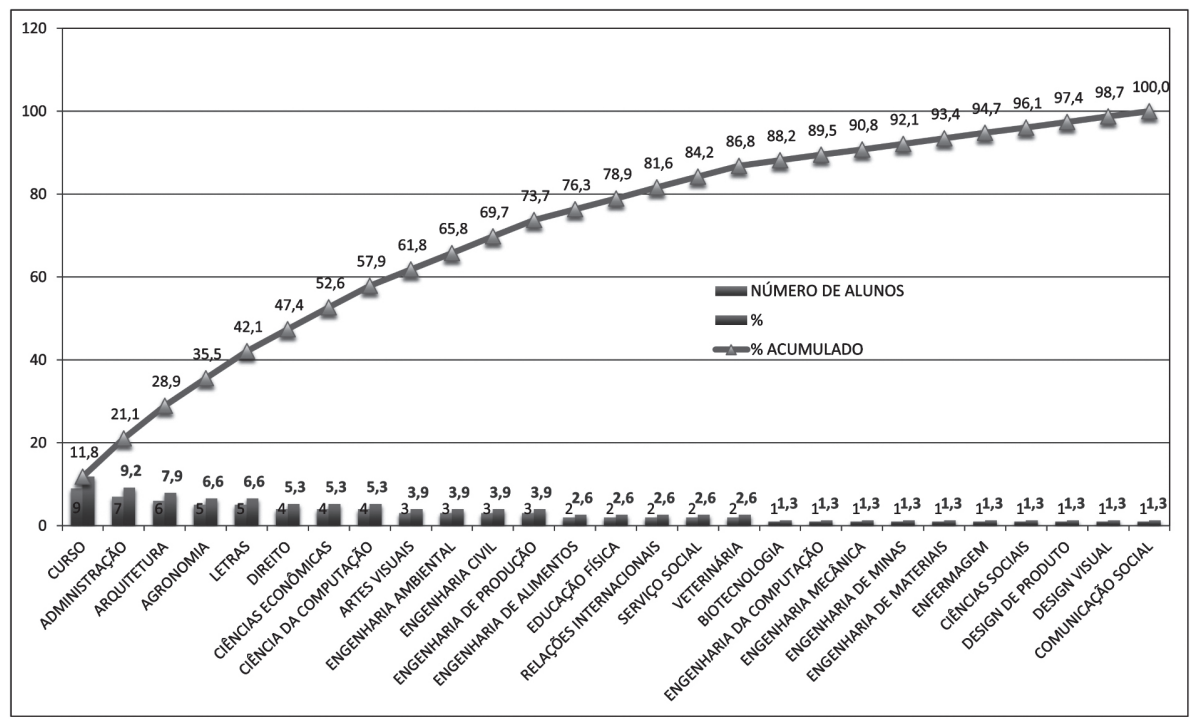

Fonte: elaboração própria.

\section{Resultados do estudo e discussão}

Neste estudo avaliativo considerando a opinião dos universitários estrangeiros em mobilidade, que passaram pelo menos um semestre na UFRGS, prestamos especial atenção à dimensão intercultural, entendendo que esta contribuiria com elementos qualitativos de avaliação inseridos nos programas de mobilidade, uma vez que as avaliações tem-se centrado em fatores quantitativos. Cabe destacar que a análise da qualidade das ações de internacionalização da UFRGS está relacionada, também, à análise dos indicadores de interculturalidade, adiante expostos.

Como em toda cultura um dos elementos mais representativos é o conhecimento e o reconhecimento dos idiomas, a subdimensão linguística foi medida através de diversos itens, a seguir comentados.

As respostas quantitativas sobre o interesse e o conhecimento do idioma de origem dos alunos visitantes por parte da comunidade universitária, receberam 
$70 \%$ das avaliações positivas, no que se refere a dirigirem-se aos alunos estrangeiros em sua própria língua (talvez isto se explique pelo elevado número de alunos hispano-falantes) e um porcentagem ainda maior ( $90 \%$ dos alunos), afirmam que os colegas, os professores e os funcionários demonstram interesse pelo idiomas dos alunos estrangeiros.

De forma aparente, a maioria dos estudantes que participam dos programas de mobilidade tem um especial interesse em aprender idiomas (e, portanto, se entende que também há interesse por outras culturas), uma vez que até $83 \%$ deles relataram haver realizado intercâmbios linguísticos com indivíduos de outros países antes de sua estadia na UFRGS. Contudo, somente 19\% dos estudantes em mobilidade incoming na UFRGS realizam cursos específicos de "português para estrangeiros" oferecidos pela universidade. Estes cursos foram bem classificados qualitativamente, ainda que existam algumas queixas sobre o preço e a diversidade de níveis de conhecimento em um mesmo grupo, questão que pode residir no fato das aulas serem, atualmente, ministradas por alunos do curso de graduação em Letras, com frágil supervisão dos docentes da universidade e ocasionar, eventualmente, um descuido no reposicionamento do estudante estrangeiro ao nível adequado. Ainda, preocupante é a razão atribuída por um aluno que afirmou não ter se matriculado no curso de português porque "não havia vaga", uma vez que o curso deveria ser capaz de cobrir todas as solicitações, de uma forma ou de outra, já que o conhecimento da língua do país de acolhimento resulta diretamente no aproveitamento da estadia, tanto no seu aspecto acadêmico como social.

Finalmente, uma pergunta indagava se os alunos tinham sido diretamente convidados a apresentar características de sua língua e cultura na sala de aula, ante seus pares. Apenas $25 \%$ respondeu ter exposto algumas informações sobre sistemas de saúde, bolsa de estudos ou sobre seu próprio programa de intercâmbio. Evidencia-se, pelo detalhe das respostas analisadas, que não houve, em nenhum caso, espaço para um intercâmbio cultural além de meras informações sobre serviços, a fim de comparar os sistemas. Este dado é relevante na construção de um currículo de formação de professores para a internacionalização, caso a universidade tenha a intenção de investir nesse sentido, conforme analisamos no apartado teórico, a partir dos apontamentos realizados no estudo de Leask (2005) sobre os professores internacionais como gestores de entornos interculturais. Neste sentido, poderia integrar o currículo do Programa de Atividades de Aperfeiçoamento Pedagógico - PAAP, que segundo a Pró-Reitoria de Graduação da UFRGS, proporciona aos docentes da UFRGS a possibilidade de formação continuada, a partir da reflexão de natureza didático-pedagógica acerca do fazer docente. 
Internacionalização da educação superior: a dimensão intercultural e o suporte institucional na avaliação da mobilidade acadêmica

A subdimensão que aborda diferentes aspectos culturais diretamente contém uma série de perguntas que fornecem informações sobre a opinião dos alunos em mobilidade e que nos dão pistas para medir a competência intercultural, como veremos a seguir.

As relações sociais são essenciais e parecem implícitas em um programa de mobilidade acadêmica. Consequentemente, no item que perguntou se durante a estadia houve convívio com brasileiros, obteve-se apenas $6 \%$ de respostas negativas pois, maioritariamente, os jovens se relacionam com outros estudantes brasileiros $(79 \%)$, como é de se esperar. O positivo é que a análise qualitativa não deixa dúvidas de que o resultado é bom em todos os casos, exemplificados na declaração de um aluno que colocou que a experiência "foi ótima, que aprendeu muito com o convívio", além do aprendizado acadêmico, as relações humanas favorecem o conhecimento e o reconhecimento cultural mais do que qualquer tratado teórico.

Várias perguntas indagavam sobre a participação dos alunos estrangeiros em atividades estudantis e de extensão cultural, mas as respostas demonstram uma fragilidade neste aspecto, uma vez que $15 \%$ dos entrevistados responderam à primeira questão de modo positivo e apenas $6 \%$ avaliaram positivamente a participação em atividades de extensão cultural. Cabe destacar que, segundo os dados do sítio web da universidade (2014), existiam 2.081 atividades de extensão (atividades acadêmicas) com 25.313 alunos participantes e 1.179 atividades culturais contando com a participação de 112.813 estudantes. nas diferentes ações. Talvez esses aspectos devam ser reforçados a partir dos próprios programas de mobilidade, uma vez que a participação em eventos socioculturais promovidos pela universidade, deve ajudar o estudante a alcançar uma sólida competência intercultural, ao facilitar o acesso ao conhecimento e reconhecimento das diferentes manifestações socioculturais. O resultado será sempre interessante e bem avaliado, como se lê no detalhe de uma resposta "Participei na AIESEC. foi uma experiência muito boa, conheci pessoas e a cultura brasileira e aprendi muito mais".

Por fim, quando se perguntou especificamente sobre a participação em um evento popular gaúcho, obtivemos as respostas cuja análise melhor manifesta o interesse do nosso estudo nesta dimensão. Evidencia-se o interesse de mais da metade dos alunos (54\%) em participar de eventos desta natureza, com o feedback extremamente positivo em todos os casos de alunos que tiveram contato com eventos da cultura regional. Consideramos, portanto, que resulta culturalmente marcante participar das atividades da cultura gaúcha. Um elemento qualitativo associado com a mobilidade dos estudantes é que o aluno conhece, em primeira mão, as particularidades culturais das regiões que não 
correspondem, em muitos casos, com o que foi aprendido nos países de origem devido aos estereótipos folclóricos.

\section{Conclusões e Prospectivas}

Em um artigo intitulado “Cinco mitos da internacionalização”, Knight (2011) indagou sobre a ideia da internacionalização como substituta da qualidade, o papel de estudantes estrangeiros como agentes da internacionalização, os acordos institucionais e a certificação internacional como indicadores do nível de internacionalização e a internacionalização como estratégia para alcançar posições altas nos rankings de universidades.

Compreendendo que a mobilidade incoming assume a perspectiva do país que recebe os estudantes estrangeiros, o fluxo de alunos em uma instituição é considerado um forte indicador de atratividade à instituição, de acordo como relatório de implementação do Processo de Bolonha (2015). Sendo assim, para que se efetive a qualidade da educação superior a partir da mobilidade acadêmica, a instituição deve intensificar as ações que promovem a qualidade da dimensão intercultural, medi-la através da opinião dos estudantes, adotando estratégias para qualificar a formação intercultural dos alunos em sala de aula e nas atividades estudantis e de extensão.

No presente estudo, abordamos alguns destes temas, destacando o papel dos estudantes de outros países como agentes da internacionalização. Neste sentido e acordo com Knight (2012, p. 2)

[...]a internacionalização pode, por exemplo, ajudar no desenvolvimento do conhecimento, das habilidades e dos valores internacionais e interculturais entre os estudantes por meio de melhorias no ensino e na aprendizagem, através da mobilidade internacional e de um currículo que inclua elementos comparativos, internacionais e interculturais.

Referimos na seção teórica deste estudo que é interessante saber, em primeira mão, quais são os elementos culturais significativos dos países de intercâmbio acadêmico para não se perder a oportunidade de "conhecer" para além do conteúdo acadêmico. Também que para conhecer e reconhecer-se nos outros e para ajudar a superar essas primeiras impressões de elementos culturais "genéricos", faz-se necessário divulgar e disseminar, em profundidade, as características específicas dos diferentes povos e culturas.

Consequentemente, neste estudo para avaliar a qualidade da mobilidade, seja para a universidade, a nível pessoal, ou para o sistema, definimos os indicadores qualitativos da mobilidade e avaliamos a trajetória formativa dos alunos que estavam em mobilidade, a partir da mensuração de dimensões, como (1) a in- 
Internacionalização da educação superior: a dimensão intercultural e o suporte institucional na avaliação da mobilidade acadêmica

tercultural e seus aspectos linguísticos e culturais, cuja valoração foi realizada através de um questionário elaborado por Díaz García e outros autores (2010); (2) a relativa à capacidade ou disposição para desempenhar determinadas tarefas ou funções, medida, através do background prévio à mobilidade e (3) as competências adquiridas com a mobilidade.

Os resultados desta pesquisa de avaliação dos alunos estrangeiros em mobilidade na UFRGS apontaram diversos aspectos positivos no que se refere ao interesse da comunidade acadêmica pelo idioma e cultura dos estudantes estrangeiros, à integração entre os estudantes e a satisfação dos alunos em mobilidade em conhecer, através de eventos regionais, a cultura local. Por outro lado, evidenciam relativa debilidade na oferta do idioma pela universidade, nas escassas oportunidades para a troca/formação intercultural em sala de aula e na fragilidade da participação nas atividades estudantis e de extensão proporcionadas aos alunos em mobilidade incoming.

Finalmente, o estudo demonstrou a importância de (1) qualificar as ações da instituição para receber maior número de alunos estrangeiros; (2) atentar às debilidades destacadas como o fortalecimento da oferta de idiomas pela instituição, especificamente da oferta da aprendizagem da Língua Portuguesa; (3) investir e planejar a formação dos professores para que estes atuem no sentido de dar mais qualidade à mobilidade e, por esta via, para a internacionalização da instituição; e (4) fomentar a participação dos estudantes nas atividades estudantis e de extensão.

A relevância deste estudo poderá residir no fato do Brasil, atualmente, estar alinhado ao modelo europeu de internacionalização e circulação acadêmica e, por conseguinte, a proposta de avaliar para aprender e qualificar a gestão da mobilidade torna-se substancial, uma vez que as instituições buscam desenvolver ações de articulação e cooperação. Em consequência, o fortalecimento de critérios de qualidade será importante para informar aos estudantes sobre a instituição na qual pretendem estudar, para aumentar a atratividade dos estudantes em relação a instituição e, consequentemente, avançar no processo de internacionalização da educação superior.

Nesta direção, a fim de comparar os resultados aqui obtidos e para avançar no planejamento das políticas e práticas institucionais locais, corroborando com o delineamento traçado na Convenção para a Proteção e Promoção da Diversidade das Expressões Culturais (UNESCO, 2005), temos como prospectiva avaliar, a partir do modelo proposto, os alunos que vão em mobilidade através do Programa Ciência sem Fronteiras, uma vez que, como ressaltamos anteriormente, este programa é o principal investimento do governo brasileiro 
em termos de mobilidade acadêmica e de intercâmbio, que visa o desenvolvimento social e econômico do país. Com ele, o país cresce em importância política e em desenvolvimento econômico, científico e tecnológico. Retomando as palavras de Castro e Cabral Neto (2012, p. 38) "o modo como os países e regiões se inserem no cenário mundial [...], influi no processo de receber os alunos e mobilidade". Dessa maneira, pactuamos que se inicia um efetivo processo de internacionalização da educação superior no país e, sendo assim, torna-se imperativo definir os objetivos nacionais e institucionais que se deseja alcançar com a mobilidade para que se possa definir objetivamente os critérios de qualidade deste processo.

\section{Referências}

ALTBACH, Philip; KNIGHT, Jane. The Internationalization of Higher Education: Motivations and Realities. Journal of Studies in International Education, Los Angeles, n. 3/4, p. 290-305, 2007.

ALTBACH, Philip. Globalization and the University: Myths and Realities in the Unequal World. Tertiary Education and Management, Lancaster, UK, n. 1, 2004. Disponível em: <www.link.springer.com/article>. Acesso em: 2 ago. 2014.

BRASIL. Programa Ciência sem Fronteiras. Disponível em: <http://www. cienciasemfronteiras.gov.br/web/csf/o-programa>. Acesso em 15 set. 2015.

BOTTO, Mercedes. La transnacionalización de la educación superior: ¿qué papel juegan los nuevos regionalismos en la difusión de estas ideas? El caso del Mercosur en perspectiva comparada (1992-2012). RIES, México, v. 6, n. 16, p. 90-109, 2015.

BRASIL. Decreto no 7.642 de 13 de dezembro de 2011. Institui o Programa Ciência Sem Fronteiras. Disponível em: <http://www.planalto.gov. br/ccivil_03/_Ato2011-2014/2011/Decreto/D7642.htm>. Acesso em 15 nov. 2014.

BRASIL. Ciência e Tecnologia. Desenvolvimento Regional Sustentável. Tecnologia social. Disponível em: http:/www.brasil.gov.br/sobre/cienciae-tecnologia/desenvolvimento-sustentavel/tecnologia-social. Acesso em: 19 set. 2013.

CABRERA, F.; ESPIN, J. Medición y evaluación educativa. Barcelona: PPU, 1986. 
CASTRO, A. A.; CABRAL NETO, A. O ensino superior: a mobilidade estudantil como estratégia de internacionalização na América Latina. Revista Lusófona de Educação, n. 21, p. 69-96, 2012.

CATANI, Afrânio Mendes. Processo de Bolonha e Impactos na América Latina: incursão preliminar em produções bibliográficas recentes, 2010. Disponível em: <www.anpae.org.br/iberolusobrasileiro2010/cdrom/4.pdf> Acesso em 5 jan. 2011.

DALE, Roger. Globalização e educação: demonstrando a existência de uma 'cultura educacional mundial comum' ou localizando uma 'agenda globalmente estruturada para a Educação. Educação \& Sociedade, Campinas, v. 25, n. 87, p. 423-460, maio/ago. 2004.

DE WIT, Hans. Globalización e internacionalización de la educación superior [introducción a monográfico en línea]. RUSC: Revista de Universidad y Sociedad del Conocimiento, Barcelona, v. 8, n. 2, p. 77-84, 2011.

DIAS SOBRINHO, José. Dilemas da educação superior no mundo globalizado: sociedade do conhecimento ou economia do conhecimento? São Paulo: Casa do Psicólogo, 2005.

. O Processo de Bolonha. In: PEREIRA, Elisabete M. A.; ALMEIDA, Maria de Lourdes P. (Orgs.). Universidade contemporânea: políticas do Processo de Bolonha. Campinas: Mercado das Letras, 2009.

Democratização, qualidade e crise da educação superior: faces da exclusão e limites da inclusão. Educação \& Sociedade, Campinas, v. 31, n. 113, p. 1223-1245, out./dez. 2010.

DÍAZ GARCÍA, María Teresa et al. La competencia intercultural en un cuestionario en línea de satisfacción del alumnado de programas de movilidad en la Universidad de Santiago de Compostela (USC). 2010. Disponível em: <http://www.grupodelinguas.com/files/Cuestionario.pdf $>$. Acesso em 18 jan. 2015.

ENDERS, Jurgen. Higher education, internationalization, and the nationstate - Recent developments and challenges to governance theory. Higher Education, New York, n. 47, p. 361- 382, 2004. 
EUROPEAN COMMISSION/EACEA/EURYDICE.The European

Higher Education Area in 2015: Bologna Process Implementation Report. Luxembourg: Publications Office of the European Union, 2015.

GACEL-AVILA, J. The Internationalisation of Higher Education: A Paradigm for Global Citizenry: Higher Education, New York. v. 2, p.121136, 2005.

GONZÀLEZ MEDIEL, Olga. Cap a un curriculum intercultural a primària. 2008. 180p. Tese (Doutorado) - Universitat de Barcelona, Barcelona, 2008

GONZÀLEZ MEDIEL, Olga. Diversidad cultural y educación: el sistema educativo Catalán. In: RAMOS, Fernando (Ed.). Investigación en educación y derechos humanos, Coímbra, 2009. p. 139-159.

HERNÁNDEZ R.; FERNÁNDEZ C.; BAPTISTA P. Metodología de la Investigación. México: Mc Graw-Hill Interamericana, 1991.

KNIGHT, Jane. Internationalisation: Key concepts and Elements. In: EUROPEAN UNIVERSITY ASSOCIATION. Internationalisation of European Higher Education. Berlin: Raabe, 2010.

. Five Myths about Internationalization. International Higher Education, Boston, v. 62, p. 14-15, 2011.

. Student Mobility and Internationalization: trends and tribulations.

Research in Comparative and International Education, Oxford, n.7, v. 1, p. 20-33, 2012.

\section{LEASK, B. Internationalisation of the Curriculum and Intercultural} Engagement: A Variety of Perspectives and Possibilities. Australian International Education Conference. Gold Coast, Queensland, p. 1-9, 2005.

LIMA, M. C.; MARANHÃO, C. M. do S. de A. O sistema de educação superior mundial: entre a internacionalização ativa e passiva. Avaliação, Campinas; Sorocaba, v. 14, n. 3, p. 583-610, 2009.

ROBERTSON, S. L. O processo de Bolonha da Europa torna-se global: modelo, mercado, mobilidade, força intelectual ou estratégia para construção do Estado? Revista Brasileira de Educação, Rio de Janeiro, v. 14, n. 42, p. 407-600, 2009. 
TEICHLER, Ulrich. The Changing debate on internationalization of higher education. Higher Education, New York, n. 48, p. 5-46, 2004.

UNESCO. Declaração Mundial sobre Educação Superior para o Século XXI: visão e ação. Paris: UNESCO, 1998. Disponível em: <http://unesdoc. unesco.org/images/0022/002253/225383s.pdf >. Acesso em: 6 set. 2015.

UNESCO. Convenção da Unesco sobre a Proteção e a Promoção da Diversidade Cultural. Lisboa, 2005.

UNESCO. Global Flow of Tertiary-Level Students, 2015. Disponível em: $<$ http://www.uis.unesco.org/Education/Pages/international-student-flow-viz. aspx $>$. Acesso em: 5 abr. 2015.

VAN DAMME, Dirk. Quality issues in the internationalization of higher education. Higuer Education, New York, n. 41, p. 415-441, 2001.

VEIGA, R. Internacionalização das instituições de ensino superior em Portugal: proposta de metodologia para a construção de indicador do grau de internacionalização. 2012. Dissertação (Mestrado em Negócios Internacionais) - Escola Superior de Tecnologia e Gestão (ESTG) do Instituto Politécnico de Leiria, Leiria, 2012.

VEGA, Alfredo Pena et al. O Processo de Bolonha no Ensino Superior da América Latina. Estudo de Casos. Observatório Internacional de Reformas da Universidade. 2009. Disponível em: < http://gulbenkian.pt/media/files/ agenda/eventos_2009/futurodebologna. Acesso em: 08 mar.2011.

Maria Beatriz Luce - Universidade Federal do Rio Grande do Sul Porto Alegre | RS | Brasil. Contato: lucemb@ufrgs.br

Caterine Vila Fagundes - Universidade Federal do Rio Grande do Sul Porto Alegre | RS | Brasil. Contato: caterine.fagundes@gmail.com

Olga González Mediel - Universidade de Barcelona

- Barcelona | Espanha. Contato: ogonzalez@ub.edu

Artigo recebido em 16 de novembro de 2015 e aprovado em 10 de abril de 2016. 
